\title{
Costello syndrome: two cases with embryonal rhabdomyosarcoma
}

\author{
B Kerr, O B Eden, R Dandamudi, N Shannon, O Quarrell, A Emmerson, E Ladusans, \\ $M$ Gerrard, D Donnai
}

North West Regional

Genetic Service, St

Mary's Hospital,

Manchester M13 0JH,

UK

B Kerr

D Donnai

Department of

Oncology, Royal

Manchester Children's

Hospital, Manchester,

UK

O B Eden

R Dandamudi

North Trent Clinical

Genetics Service,

Sheffield, UK

N Shannon

O Quarrell

Department of

Paediatrics, St Mary's

Hospital, Manchester,

UK

A Emmerson

Department of

Cardiology, Royal

Manchester Children's

Hospital, Manchester,

UK

E Ladusans

Sheffield Children's

Hospital, Sheffield, UK

M Gerrard

Correspondence to:

Dr Kerr.

Received 4 March 1998

Revised version accepted for publication 12 May 1998

\begin{abstract}
Costello syndrome is a well delineated mental retardation syndrome of unknown aetiology in which the occurrence of benign tumours, especially papillomata, is recognised. We report two children in whom the diagnosis of Costello syndrome was made in the first months of life, who both developed a retroperitoneal embryonal rhabdomyosarcoma. Although not previously reported, the occurrence of this relatively uncommon childhood tumour in two girls with Costello syndrome suggests that an increased risk of malignancy may be part of this condition. The genetic basis of this susceptibility requires further clarification.

$(\mathcal{F}$ Med Genet 1998;35:1036-1039)
\end{abstract}

Keywords: Costello syndrome; rhabdomyosarcoma

In 1971 and 1977, Costello described two unrelated children with features of poor postnatal growth, mental retardation, curly hair, loose skin of the hands and feet, distinctive facies, and nasal papillomata. Although no further reports appeared until $1991,{ }^{2}$ by 199616 cases in English publications where the authors used the designation Costello syndrome were able to be reviewed by $\mathrm{Dr}$ Costello ${ }^{3}$ in an update on his original patients.

Borochwitz et $a l^{4}$ reported five patients with a previously unrecognised syndrome and proposed naming it the facio-cutaneous-skeletal syndrome. It has been suggested that these patients and three reported by Berberich et at also have the Costello syndrome. ${ }^{67}$ Several other reports ${ }^{8-12}$ bring the total number of published cases to 31 .

Although the similarities between Costello syndrome, Noonan syndrome, and the cardiofacio-cutaneous (CFC) syndrome have long been recognised, ${ }^{2}$ a number of characteristic findings in Costello syndrome are infrequent or absent in Noonan and CFC syndromes. ${ }^{23}$ In particular, the natural history of Costello syndrome is very striking ${ }^{13}$ with two distinct disease phases, the first characterised by a severe failure to thrive following normal or increased birth weight and often polyhydramnios, and the second by a clinical picture which resembles a storage disorder.

Children with Costello syndrome tend to develop benign primitive ectodermal tumours Papillomas may occur at various ages in nasal, perioral, and anal areas and a calcified epithelioma has occurred. ${ }^{14}$ Zampino et al ${ }^{13}$ reported a child with Costello syndrome who was diag- nosed to have ganglioneuroblastoma, a tumour of neuroectodermal origin, at the age of 17 months. An adult with Costello syndrome, unilateral cataract, and a unilateral acoustic neuroma has been reported. ${ }^{15}$

We describe here two children with Costello syndrome, both of whom have developed in early life a pelvic embryonal rhabdomysosarcoma, a tumour of mesenchymal origin.

\section{Case reports}

CASE 1

A 3 year old girl, the only child of unrelated parents of Anglo-Saxon origin, first came to medical attention prenatally when an ultrasound scan at 16 weeks' gestation showed nuchal thickening with a normal female karyotype on amniocentesis. On subsequent scans, increased liquor volume and an abnormal hand posture with flexion and ulnar deviation at the wrists was noted. She was born at 38 weeks' gestation by elective caesarean section.

At birth her weight was $3470 \mathrm{~g}$ (90th centile) and her head circumference was $37 \mathrm{~cm}$ (above the 97 th centile). She fed poorly from the beginning and was admitted to neonatal intensive care with transient hypoglycaemia. She developed a supraventricular tachycardia with ectopics on day 10. She responded to, and remained well, on oral digoxin and flecainide. Echocardiogram showed a patent foramen ovale and mild pulmonary valve stenosis. She was eventually discharged home at 1 month of age.

In the newborn period, she was noted to have a flat nasal bridge with epicanthus and hypertelorism, downward slanting palpebral fissures, and large, upturned ear lobes. Her hands were tightly clenched and her wrist posture was abnormal with persisting ulnar deviation. Hyperextensibility of the small joints of the hands was noted with deep set nails and deep vertical foot creases.

Her feeding difficulty persisted with vomiting despite medical management of gastrooesophageal reflux. By 3 months, she had made little developmental progress and, although her head circumference remained above the 90th centile, her weight was on the 10 th centile. The diagnosis of Costello syndrome was made at this time on the basis of her facial features, clinical course, and striking excess palmar skin (fig 1).

Cerebral CT scan and subsequent MRI showed only minor prominence of the lateral and third ventricles. Formal ophthalmological assessment at 10 weeks was consistent with delayed visual maturation. Blood and skin chromosomes were both normal. 

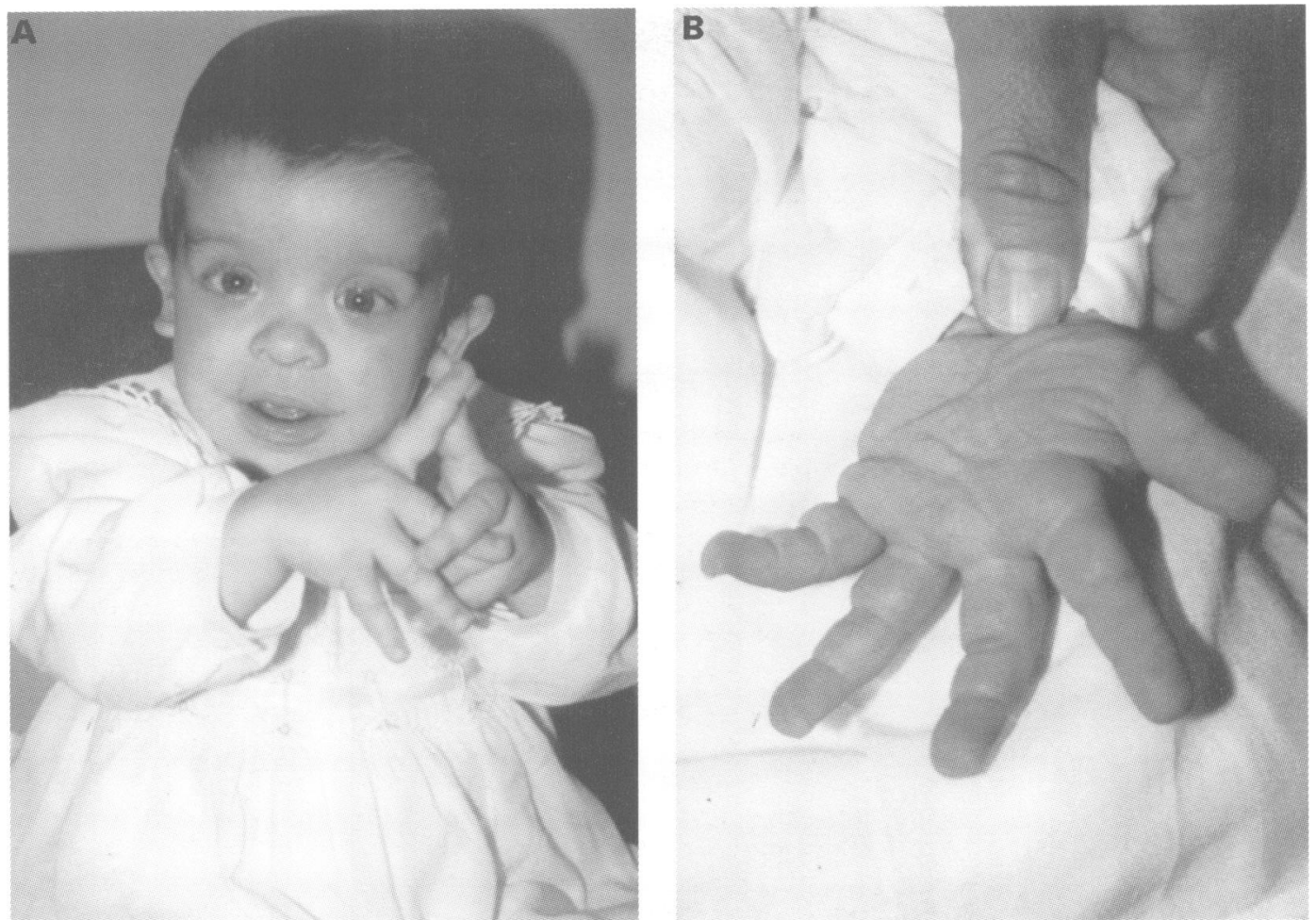

Figure 1 (A) Case 1 signing "home" at the age of 3. (B) Case 1 showing excess palmar skin with deep creases and marked hyperextensibility of the small joints of the hand.

She continued to have intense problems with feeding and slow weight gain. By 5 months her weight and height were below the 3 rd centile and have continued to parallel the 3 rd centile since. She initially was tried on intermittent nasogastric tube feeding to supplement calorie intake. This having failed, she went on to have regular night time tube feeding. At 6 months, she began to fix and follow and smiled. She rolled and began to vocalise at 8 months. She was sitting unaided at 18 months but was unable to pull to a sitting position on her own until the age of 2 .

She had problems with constipation and recurrent chest infections but no further episodes of supraventricular tachychardia.

At the age of 2 years 4 months she was admitted to hospital with a four week history of progressive vomiting and constipation. Her parents noted marked abdominal distension just before admission. She was clinically unwell with acute bowel obstruction. Ultrasound and MRI imaging of her abdomen showed a large mass measuring $10 \times 9 \times 8 \mathrm{~cm}$ arising from the left psoas major muscle. This mass compressed the left ureter, causing hydronephrosis. The ureteric obstruction was relieved surgically and a biopsy of the mass taken. Histology was reported as embryonal rhabdomyosarcoma. No metastatic spread was found on staging investigations. She received chemotherapy immediately, but in view of her clinical condition, standard rhabdomyosarcoma therapy was modified to vincristine, actinomycin, and cyclophosphamide. Ten days later she became acutely unwell with bowel obstruction. Adhesions of the bowel were relieved and, at this second laparotomy, major tumour debulking was performed. She was continued on chemotherapy using ifosfamide, vincristine, and actinomycin. After the second course, when she developed ifosfamide induced encephalopathy, she was changed back to pulses of vincristine, actinomycin, and cyclophosphamide given every three weeks for nine courses. She expectedly had problems with nutrition and febrile neutropenic episodes. Despite regular physiotherapy her Achilles tendon contractures became worse while on chemotherapy, probably exacerbated by vincristine. A tendon releasing procedure has been performed.

She is now almost a year off treatment and has remained in remission, confirmed by regular scanning. At the age of 3 years 9 months, she is a happy, sociable, and curious little girl who is able to use many signs and a number of words with meaning. Her food remains liquidised but she eats a variety of foods in larger quantities and will attempt to feed herself with a spoon. She has been walking with a frame for the last month and has taken a few steps alone. Formal psychometric assessment has shown a scatter in performance with the highest scores being achieved in the personal-social domain and the lowest in locomotion and eye-hand coordination.

CASE 2

A $3 \frac{1}{2}$ year old girl, the third child of unrelated, Anglo-Saxon parents, was born at 38 weeks' gestation after a pregnancy complicated by polyhydramnios. Her birth weight was $3250 \mathrm{~g}$ (50th centile) and head circumference was $38.3 \mathrm{~cm}$ (97th centile). She was transferred to the Special Care Unit shortly after birth because of respiratory distress. Subsequently she had feeding difficulties and persistent vomiting which was unresponsive to all forms of medical therapy. 


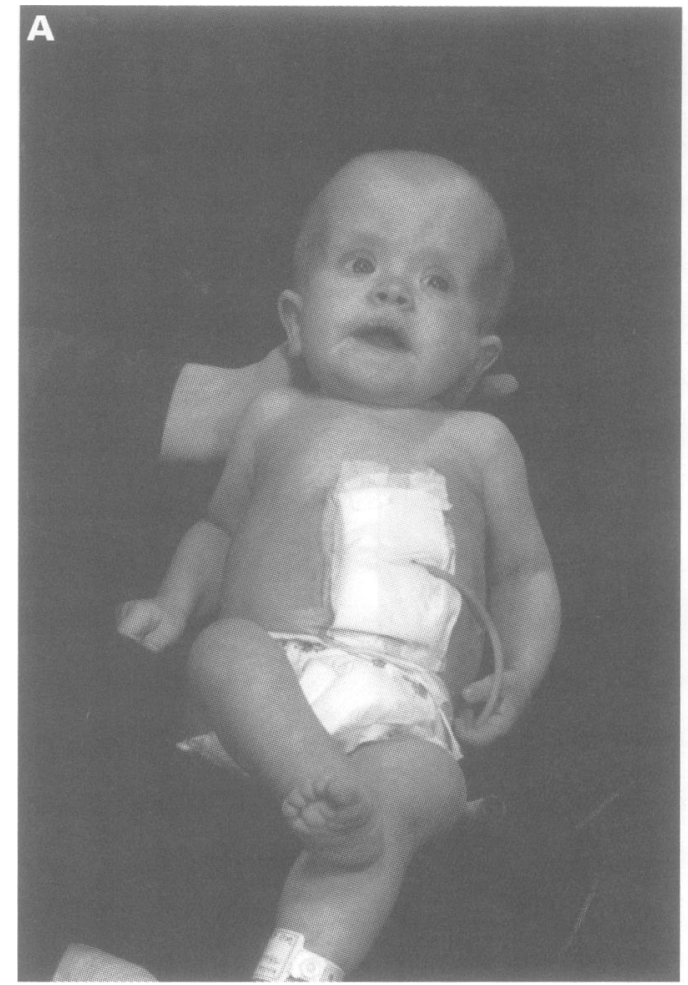

Figure 2 (A) Case 2 at 15 months. (B) Excess palmar skin. (C) Case 2 at 3 years.

At 4 months, she was re-referred to a paediatrician for investigation of persistent failure to thrive and vomiting despite continuous nasogastric feeds. Upper gastrointestinal endoscopy showed mild inflammation at the lower end of the oesophagus while a 24 hour $\mathrm{pH}$ study, on antireflux therapy, showed no residual reflux. Following her endoscopy, she had several self-correcting episodes of supraventricular tachychardia and bundle branch block. A contrast swallow showed poor suckswallow coordination.

She was noted at birth to have dysmorphic features and by 4 months these had become more prominent. She had macrocephaly with a prominent occiput and frontal bossing. She had a depressed nasal bridge with anteverted nares, low set, posteriorly rotated ears, prominent epicanthic folds, and a large mouth. Fetal finger pads were noted along with long fingers and toes and joint laxity. She had loose skin and increased creases on her palms and soles. It was evident at 4 months that her development was significantly delayed and she was hypotonic. A cerebral CT scan showed poor grey-white matter differentiation and increased CSF spaces.

A diagnosis of Costello syndrome was made at 10 months based on her evolving phenotype and striking failure to thrive (fig $2 \mathrm{~A}, \mathrm{~B}$ ). She was readmitted for a repeat 24 hour $\mathrm{pH}$ probe which showed mild reflux and it was decided that since she continued to be dependent on nasogastric tube feeds she should have a gastrostomy and Nissen's fundoplication.

She has continued to grow below the 0.4 th centile despite gastrostomy feeds and trials of calorie supplements and has only made slow progress with oral feeds. She will now take fluids by mouth but is not interested in food and usually chokes on it. Her general development
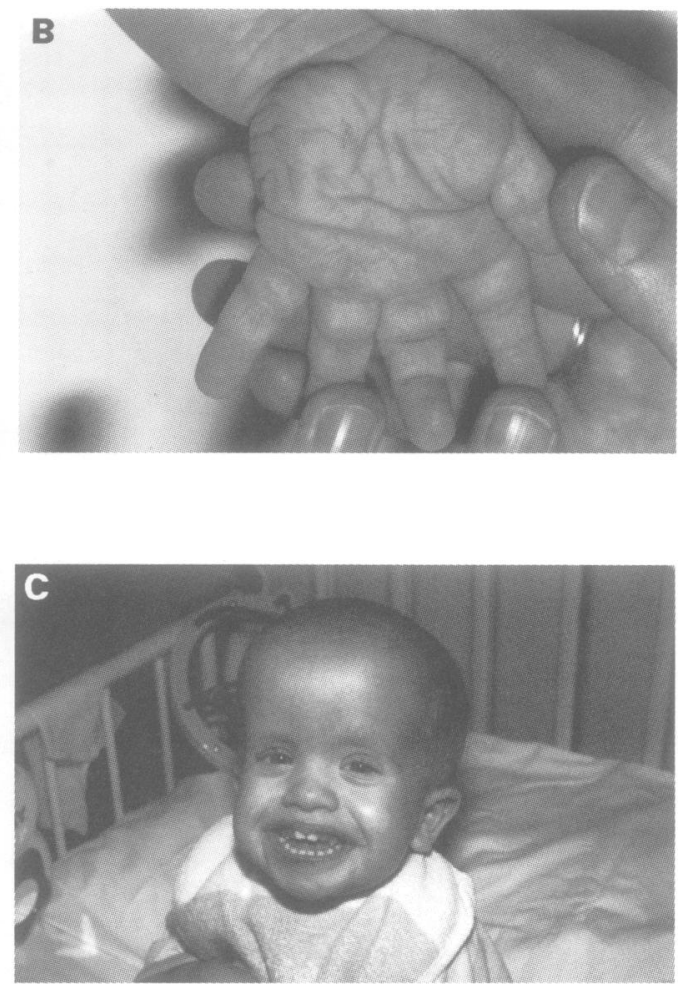

has been significantly delayed. She started to babble at 22 months but has not gained any words as yet. She now has 12 Makaton signs, can indicate wants by pointing, and shows a level of understanding above her verbal skills while playing (fig $2 \mathrm{C}$ ). She started to sit alone at 20 months and at 23 months was bottom shuffling. She was pulling herself up at 3 years and is now cruising on furniture, but at 4 years is not walking independently and is still unable to roll in either direction.

At 3 years 2 months, her mother noted an abdominal mass. She was otherwise well though tolerating slightly less gastrostomy feed than usual. Examination confirmed a firm mass arising from the pelvis. CT scan showed a vascular mass closely apposed to the anterior abdominal wall and possibly infiltrating it. No intra-abdominal lymphadenopthy could be seen and the liver looked normal.

At operation, the mass appeared to arise from the urachus and was closely adherent to the bladder. The upper part of the bladder was resected en bloc with the encapsulated tumour. Histology showed an embryonal rhabdomyosarcoma extending up to the resection margin. Staging investigations showed no evidence of metastatic disease.

She was treated with chemotherapy, initially ifosfamide, actinomycin, and vincristine. After four courses, cyclophosphamide was substituted for ifosfamide because of haemhorrhagic cystitis. Treatment was also complicated by recurrent episodes of moderately severe diarrhoea and febrile neutropenia requiring readmission to hospital.

CT examination of the abdomen and pelvis after three courses of chemotherapy showed no residual tumour. Treatment was completed after six courses of chemotherapy and, six months off treatment, she remains well. 


\section{Discussion}

The clinical features and natural history of both of these cases is consistent with the diagnosis of Costello syndrome. Martin and Jones ${ }^{6}$ suggested that the major manifestations of Costello syndrome are (1) postnatal growth deficiency, (2) developmental delay, (3) relative macrocephaly, (4) coarse face, (5) thick ears, (6) thick lips, (7) depressed nasal bridge with anteverted nares, (8) excess skin, (9) thick palms and soles, (10) short neck, (11) curly hair, (12) nasal papillomata, and (13) sociable personality. Equally important in the diagnosis is the combination of these features with the striking clinical history of early failure to thrive and cardiac and skeletal abnormalities. ${ }^{13}$

The aetiology of Costello syndrome remains unknown. Sporadic dominant mutations with gonadal mosaicism or else genetic heterogeneity as the explanation for the occasional sib recurrence has been suggested. ${ }^{16}$ Sialuria with normal sialic acid in skin fibroblasts has been documented in two patients. ${ }^{17} \mathrm{Di}$ Rocco et $a l^{17}$ also noted the similarities between the early stages of Costello sydnrome and leprachaunism and speculated that the IGF2 receptor may be involved in pathogenesis. Disruption of elastin fibres has been shown in two patients, one of whom died of rhabdomyolysis at six months. ${ }^{10}$ Normal elastin fibres have been reported in another case..$^{18} \mathrm{~A}$ patient with a de novo apparently balanced translocation has been described with the karyotype $46, \mathrm{XX}, \mathrm{t}(1 ; 22)(\mathrm{q} 25 ; \mathrm{q} 11)$. $^{12}$

Soft tissue sarcomas (STS) account for 4-8\% of all childhood tumours in the USA and western Europe and have a combined age specific rate of 5-9 per million. ${ }^{19}$ Between two-thirds and three-quarters of all STS are rhabdomyosarcomas. The occurrence of two embryonal rhabdomyosarcomas in a rare syndrome is highly suggestive of a causal link. It is of interest, given the phenotypic similarities between Noonan syndrome and Costello syndrome, that vaginal botryoid rhabdomyosarcoma has been reported in Noonan syndrome. ${ }^{20}$

Rhabdomyosarcoma (RMS) is classified conventionally into botyroid, embryonal, alveolar, and pleomorphic subtypes. As embryonal is the most common, the occurrence of the same tumour type in these two children may not be significant. RMS has been reported in association with neurofibromatosis type 1 and Beckwith-Wiedemann syndrome. More commonly RMS occurs as part of the Li-Fraumeni syndrome owing to mutations in the tumour suppressor gene TP53. Indeed, $5 \%$ of RMS are reported to be associated with a TP53 mutation. ${ }^{21}$
Our identification of two children with Costello syndrome and embryonal rhabdomyosarcoma adds to the previous recognition of an association with benign epithelial and neuroectodermal tumours. On follow up, any unusual symptoms should be investigated for the possibility of neoplasia. Further investigations of the mechanisms of tumorigenesis in Costello syndrome are required.

\section{Addendum}

The anaesthetic management of case 1 has also been reported in an anaesthetic journal. ${ }^{22}$

We acknowledge the contribution of Dr Ruth Newbury-Ecob who made the diagnosis of Costello syndrome in case 2 .

1 Costello JM. A new syndrome: mental subnormality and nasal papillomata. Aust Paediatr 7 1977;13:114-18.

2 Der Kaloustian VM, Moroz B, McIntosh N, Watters AK, Blaichman S. Costello syndrome. Am $\mathscr{f}$ Med Genet Blaichman $S$.

3 Costello JM. Costello syndrome: update on the original cases and commentary. Am 7 Med Genet 1996;62:199-201.

4 Borochowitz Z, Pavone L, Mazor G, Rizzo R, Dar H. New multiple congenital anomalies: mental retardation synmultiple congenital anomalies: mental retardation syn-
drome (MCA/MR) with facio-cutaneous-skeletal involvement. Am $\mathcal{F}$ Med Genet 1992;43:678-85.

5 Berberich MS, Carey JC, Hall BD. Resolution of the perinatal and infantile failure to thrive in a new autosomal recessive syndrome with the phenotype of a storage disorder and furrowing of palmar creases. The 11th $D W$ Smith workshop on malformation and morphogenesis, Lexington, Kentucky, 1990:76.

6 Martin RA, Jones KL. Facio-cutaneous-skeletal syndrome is the Costello syndrome. Am $\mathcal{F}$ Med Genet 1993;47:169.

7 Der Kaloustian VM. Not a new MCA/MR syndrome but probably Costello syndrome? Am $\mathcal{f}$ Med Genet 1993;47: 170-1.

8 Fryns JP, Vogels A, Haegerman J, Eggermont E, Van Den Berghe H. Costello syndrome: a postnatal growth retardation syndrome with distinct phenotype. Genet Couns 1994; tion syndrom

9 Torrelo A, Lopez-Avila A, Mediero IG, Zambrano A. Costello syndrome. F Am Acad Dermatol 1995;32:904-7.

10 Mori M, Yamagata T, Mori Y, et al. Elastic fiber degeneration in Costello syndrome. Am $\mathcal{F}$ Med Genet 1996; 61:304-9.

11 Popa M, Ioan DM, Fryns JP. Costello syndrome: report of an 8-month-old marasmic boy. Genet Couns 1996;7:27-30.

12 Czeizel EC, Timar L. Hungarian case with Costello syndrome and translocation $\mathrm{t}(1,22)$. Am 7 Med Genet 1995;57:501-3.

13 Zampino G, Mastroiacovo P, Ricci R, et al. Costello syndrome: further clinical delineation, natural history, genetic definition, and nosology. Am 7 Med Genet 1993;47: 176-83.

14 Martin RA, Jones KL. Delineation of the Costello syndrome. Am $\mathcal{F}$ Med Genet 1991;41:346-9.

15 Suri M, Garrett C. Costello syndrome with acoustic neuroma and cataract. Is the Costello locus linked to neurofibromatosis type 2 on 22q? Clin Dysmorphol (in press).

16 Lurie IW. Genetics of the Costello syndrome. Am $f$ Med Genet 1994;52:358-9.

17 Di Rocco M, Gatti R, Gandullia P, Barabino A, Picco P, Borrone C. Report on two patients with Costello syndrome and sialuria. Am f Med Genet 1993;47:1135-40.

18 Davies SJ, Hughes HE. Costello syndrome: natural history and differential diagnosis of cutis laxa. 7 Med Genet 1994;31:486-9.

19 Stiller CA, Parkin DM. International variations in the incidence of childhood soft tissue sarcomas. Paediatr Perinat Epidemiol 1994;8:107-19.

20 Khan S, McDowell H, Upadhyaya M, Fryer A. Vaginal rhabdomyosarcoma in a patient with Noonan syndrome. $f$ rhabdomyosarcoma in a patic

21 Toguchida J, Yamaguchi T, Dayton $\mathrm{SH}$, et al. Prevalence and spectrum of germline mutations of the p53 gene amon patients with sarcomas. $N$ Engl f Med 1992; 326:1301-8

22 Dearlove O, Harper N. Costello syndrome. Paediatr Anaes 1997;7:476-8. 